\title{
Family Income and Its Relation to Preschool Education in China: Empirical Research Based on CFPS Survey Data
}

\author{
Pengcheng Wang \& Xin Gong
}

Central China Normal University, Wuhan 430079, China

\begin{abstract}
Based on the data from the China Family Panel Survey, this study uses the logit model to estimate the household income effect on the chance of children's preschool attendance and their choice of preschools. The results showed that a 100\% increase in household income per capital is associated with an increase of $2.6 \%$ in the probability of a child's preschool attending. Following the classification of preschools with different characteristics, we found that household income has a large impact on children's public preschool attending. The age of children, household registration status, and the family size show statistically significant effect on the preschool attendance and a significant difference exist between urban and rural areas on this issue. Compared with those living in urban areas, rural children are more significantly influenced by family income in respect of the preschool education chance.
\end{abstract}

Best Evid Chin Edu 2019; 1(2):67-86.

Doi: 10.15354/bece.19.ar1017

Keywords: Family income; Preschool attendance; The choice of preschools

\footnotetext{
About the Author: Pengcheng Wang, College of Education, Central China Normal University, Wuhan 430079, China

Correspondence to: Xin Gong, College of Education, Central China Normal University, Wuhan 430079, China. Email: gongxin@mail.ccnu.edu.cn.

Conflict of Interests: None.
} 


\section{Research Background and Problem}

$\mathrm{I}$ $\mathrm{N}$ recent years, preschool education, as the starting point and foundation of education, has achieved remarkable progress in China. By the end of 2016, the gross enrollment rate of preschool education had reached $77.4 \%$, about $20 \%$ higher than 2010. In spite of this, there is still a significant imbalance between regional and urban-rural in the development of preschool education (Liu \& Gao, 2013; Hong \& Luo, 2012). First, government spending in preschool education has shown a central concave pattern, whereby the middle region spends the least compared to the eastern and western regions, the family cost sharing is comparatively higher in the central region, and the cost sharing structure is quite different among provinces. Secondly, there are disparities between urban and rural areas in terms of school buildings, material and teachers, and the gaps between urban and rural areas are greater than the regional differences (Wan, 2011). Moreover, opportunities for preschool education are unevenly distributed among different classes. Because the cost of preschool education is mainly shared by public finance and the families, and it has not been identified as compulsory education, the contradiction between low family income and high education cost may lead low-income families only being able to choose private kindergartens of an ordinary quality or even choosing not to send their children to kindergartens (Song \& Liu, 2013).

Many reasons have been explored to explain the unequal distribution of preschool educational opportunities. Due to the disintegration of the planned economy in China, the supply system of preschool education units adapted to the planned economy in the early stage gradually collapsed, whereas the public finance system of preschool education was not improved simultaneously (Cui et al., 2011). Since the reform of the education system in the mid-1980s, a new system is gradually taken shape in China under the Centralized Political System and actively mobilizes social forces to participate in running schools. One of the obvious changes is to encourage social forces to be involved in partial educational services. For a long time, due to the unclear nature of educational investment shared by the government, society and family, the ambiguous responsibility of the government and the imperfect budget system of preschool education, governmental financial investments in preschool education have been relatively lower (Xia et. al., 2014). At present, the financial responsibility of preschool education in China is mainly undertaken by the district, county, township, and village. The limited financial investment in China has sharply decreased in the number of public kindergartens (Bai et. al., 2012). Consequently, households need to invest more capital to compete for scarce public resources. At the same time, the market sector has gradually become an important supplier of preschool education services, which has made preschool education services become a 
purchasable product. The non-compulsory characteristic of preschool education requires families to pay for a large portion of the cost of preschool education.

Although the difficulties of entering the kindergarten have been alleviated in recent years, the expensive payment for admission is still a serious problem. Using the cumulative CPI growth index and taking inflation into account, preschool tuition fees increased 55.62 times between 1996 and 2013. Recent data showed that preschool tuition fees have reached 100,000 CNY for a year in some cities, such as Beijing, Tianjin, Nanjing, and kindergartens, with a monthly fee of more than 5,000 CNY being common in these cities. Moreover, according to a survey in some rural areas in $2011,40.3 \%$ of parents argue that preschool education costs are too high. As a result, low-income families cannot afford to send their children to enter these high-fee kindergartens, better quality and strict admission conditions. In conclusion, high tuition fees and low family income have built obstacles for many low-income children to receive preschool education.

Gaps between income and tuition fees will not only decrease the possibility of preschool education, but also exacerbate educational inequality. One of the important functions of foundation education is to fulfill equalization, that is, to help disadvantaged people achieve upward mobility through education. In order to explore the relationship between family income and choice of preschool education based on CFPS data, this study attempts to answer the following questions: (1) does family income affect the access to preschool education opportunities? (2) Does family income affect children's access to different types of kindergartens?

The rest of this study is structured as follows. The second part is the literature review, while the third part presents data, variables and analysis methods. The fourth part summarizes empirical results, and the fifth part includes the conclusion, implications and research limitations.

\section{Literature Review}

Foreign researchers have conducted extensive studies on this issue. Chiswick and DebBurman found that increasing household income can increase the likelihood of entering kindergartens for school-age children after controlling for other factors (Chiswick \& DebBurman, 2004), while Davis and Connely examined that children with better family background are more likely to enter high quality public kindergartens (Connelly, 2005). According to the U.S. Census Bureau, 67\% of children who receive early childhood education come from a family with an annual household income of more than $\$ 150,000$, while only $35 \%$ of children earning less than $\$ 10,000$ will have access to preschool education through governmental financial aid (Bennett, 2008). Fuller et al. also explained why wealthier families send their children to kindergarten earlier (Fuller, Holloway \& Liang, 1996). 
By comparing the data from different countries, the results indicate that the relationship between family income and preschool educational opportunities may show some pattern. Bassok et al. (2011) established that the relationship between household income and formal preschool education shows a "U" line, namely that children from middle-income families may have less opportunities for preschool education because families below the poverty line will receive federal government subsidies (Bassok, Fitzpatrick, \& Loeb, 2011). In many European countries, by contrast, there is no direct correlation between the enrolment of school-age children and household income. Most European countries, with the exception of Ireland and the Netherlands, provide all children aged 3-6 with at least two years of free education, which is recognized as the legal right of children from the age of three, while Belgium and France provide free preschool education from an earlier age. According to the OECD family database in $2005,100 \%$ of the children aged 3-6 attend school in Italy and France (Bai et al., 2012). However, the relationship between family in-come and children enrollment opportunity is linearly dependent in most developing countries. For example, Foguel and Veloso concluded that the average enrollment rate for children aged 4-6 in Brazil is 73\%, and the correlation between family background and enrollment rate reached $90 \%$ (Foguel \& Veloso, 2014).

In China, research has mainly concentrated in partial provinces or groups of children. Based on mixed panel data from nine provinces included in the China health and nutrition survey (CHNS), Gong et al.'s study found that the chance of preschool enrollment of rural children is increased by $7.8 \%$ and that of urban children by $7.6 \%$ for a $100 \%$ increase in household income (Gong, Xu, \& Han, 2015). A study about Chinese migrant children found that those who have agricultural household registration (in Chinese pronunciation "Hukou (户口)") status and cross-province migration are less likely to enter preschools, while those children with household educational savings have a higher chance of preschool education (Xing \& Hu, 2015). The family will face the decision of which kindergarten to choose when they have already chosen preschool education. Studies focusing on family income and kindergarten type have found a significant correlation. A survey from Nanjing province revealed that children with high-income families and parents working for governmental institutions are more likely to enter public kindergartens. Liu et al. studied 3456 children in Shenzhen, concluding that children from high-income families have the attendance opportunities of 1.82 times of that for children from middle and lowlevel families (Liu et. al., 2016). Empirical studies of preschool education choices have shown that public kindergartens tend to be more accessible to children from highly educated families.

Although the literature has not formed a unified evaluation standard for different kindergartens, some scholars still carried out research on kindergarten evaluation. Liu et al. (2008), comparing the differences of 26 kindergartens in Shanxi, found that 
public kindergartens have more obvious advantages than non-governmental kindergartens and village kindergartens, due to the financial educational funds from the state, teachers' salaries, and kindergarten management (Liu et al., 2008). For nongovernmental kindergartens, there is a positive correlation between the quality of kindergarten and entry fee, because the running cost is all shared by the market. According to the discussion above, families should pay for the cost of preschool education whether in government kindergartens or non-government kindergartens. The question is thus: what is the relationship between household income and preschool choice?

To summarize, foreign studies analyzing the relationship between family income and preschool education opportunities have revealed the relationship in detail, while the studies from China are usually constricted to partial regions, provinces, and cities. Furthermore, most of the conclusions mainly come from simple statistical description, and there is scant empirical research. Based on a national sample, this study aims to utilize the logit model to conduct an empirical estimation on the relationship between preschool attendance and household income.

\section{Data}

Data in this study are from the micro survey of China Family Panel Studies (CFPS) conducted by the China Social Science Research Center at Peking University. The CFPS sample covers 25 provinces, municipalities and autonomous regions, with a target sample size of 16,000 households ${ }^{I}$. The CFPS database conducted a baseline survey in 2010 and tracked all baseline family members, their offspring and adopted children as CFPS genetic members in 2012, 2014 and 2016. The questionnaires are divided into four types: community questionnaire, family questionnaire, adult questionnaire and children questionnaire, among which the children questionnaire is divided into two: parents answered for those under 10 and self-answered for those aged 10-15. Since the areas cover about $95 \%$ of total population, CFPS can be regarded as a nationally representative sample.

The sample used in this study is the tracking data of 2012 and 2014. ${ }^{2}$ This study selected children aged 3-6 years in the CFPS2012 as the main research object, and the main variables came from the children's questionnaire and its corresponding family questionnaire. By matching the CFPS2012 children's questionnaire with its corresponding family questionnaire, 1,195 children were successfully matched. In order to analyze and compare across different years, we successfully matched 1,015 children by using CFPS2014 data.

\section{Variables}


Dependent variable: preschool attendance and types. According to the children's questionnaire, "Is the child currently attending school/kindergarten/nursery? The research objects can be divided into two categories, namely entering the kindergarten and not entering the kindergarten.

Independent variable: household income. The measurement indicator in this study is per capita annual incomes reported by parents in the family questionnaire. In order to avoid the influence of extremum, this study truncated the extreme value of 5\% of income. Finally, the natural logarithm of income was added into the regression model.

Controlling variable: family background variables and demographic variables. Previous studies have shown that the influence of family background on educational attainment can be realized by the choice of educational resources, and families with superior capital can make choices in favor of children's educational attainment depending on their superior resources (Fang, 2011). According to Bourdieu's family capital theory, we will control for other family background factors besides household income in order to observe the independent effect of family income on preschool education admission. Therefore, other influential variables controlled in this study basically include parents' education level, occupational category, political identity, frequency of family purchasing cultural products, number of families, and whether the mother lives at home. Parents' education level is mainly coded by current education system, mainly reflecting the household cultural capital. At the same time, cultural capital can also be "expressed in the form of enduring mental and physical dispositions" (Liu et al., 2016); we will treat "whether children often go out to play with their parents" and "do your family often buy books for children?" from the children questionnaire as measurable indicators of family cultural capital. We believe that the frequency of parent-children interaction can reflect parental education philosophy to some extent, and the low-income family's spending on parenting time and educational materials are limited (Brown, 2006). The occupational category of parents is converted according to the standard occupation code of China. In the labor market, parents' income is related to their occupation to some extent. Political identity is mainly divided into party members and non-party members.

Demographic variables mainly include gender, age, and household registration status. In addition, considering that the regional gaps in economy may have an impact on the access to preschool education, this study also adds the provinces of the research objects as dummy variables to control for provincial differences. Table 1 presents the descriptive statistics of main variables. 


\section{Table 1. Descriptive Statistics for Analysis Variables.}

\begin{tabular}{|c|c|c|c|c|}
\hline Classification & Variable & Subsample & Mean & SD \\
\hline $\begin{array}{l}\text { The Dependent Varia- } \\
\text { ble }\end{array}$ & Preschool Attendance & Yes $=1, \mathrm{No}=0$ & 0.644 & 0.478 \\
\hline \multirow{9}{*}{ Individual Variables } & $\begin{array}{l}\text { Per Capita Household } \\
\text { Income }\end{array}$ & The Logarithm & 8.593 & 1.280 \\
\hline & Gender & Women $=1$, Men $=0$ & 0.459 & 0.498 \\
\hline & Age & Age of Units: & 3.968 & 0.821 \\
\hline & $\begin{array}{l}\text { Household Registration } \\
\text { Status }\end{array}$ & $\begin{array}{l}\text { Non-agricultural }=1 \text {, Oth- } \\
\text { ers }=0\end{array}$ & 0.226 & 0.418 \\
\hline & $\begin{array}{l}\text { Mother Doesn't Live at } \\
\text { Home }\end{array}$ & Yes $=1, \mathrm{No}=0$ & 0.826 & 0.378 \\
\hline & The Eastern Region & Yes $=1$, No $=0$ & 0.345 & 0.475 \\
\hline & The Central Region & $\mathrm{Yes}=1, \mathrm{No}=0$ & 0.342 & 0.476 \\
\hline & The Western Region & Yes $=1$, No $=0$ & 0.309 & 0.462 \\
\hline & $\begin{array}{l}\text { The Number of House- } \\
\text { holds }\end{array}$ & Units: Number & 5.305 & 1.743 \\
\hline \multirow{4}{*}{ Cultural Background } & $\begin{array}{l}\text { Father's Years of School- } \\
\text { ing }\end{array}$ & Years & 4.136 & 4.361 \\
\hline & $\begin{array}{l}\text { Mother's Years of School- } \\
\text { ing }\end{array}$ & Years & 1.789 & 3.332 \\
\hline & $\begin{array}{l}\text { Times of Family Trips for a } \\
\text { Month } \geq 2\end{array}$ & Yes $=1, \mathrm{No}=0$ & 0.503 & 0.500 \\
\hline & $\begin{array}{l}\text { Times of Buying Books for } \\
\text { a Month } \geq 2\end{array}$ & Yes $=1$, No $=0$ & 0.791 & 0.406 \\
\hline Social Background & $\begin{array}{l}\text { Occupational Classification } \\
\text { of Fathers }\end{array}$ & $\begin{array}{l}\text { Class Level } 9 \text { and Above } \\
=1 \text {, Others }=0\end{array}$ & 9.282 & 3.360 \\
\hline Political Background & $\begin{array}{l}\text { Is Father a Member of the } \\
\text { Party? }\end{array}$ & Yes $=1, \mathrm{No}=0$ & 0.121 & 0.326 \\
\hline \multicolumn{5}{|c|}{$\begin{array}{l}\text { Note: Parents' years of education are coded according to the Chinese current school system, specifi- } \\
\text { cally as follows: primary school }=6 \text {, junior high school }=9 \text {, senior high school/technical secondary schoo } \\
=12, \text { junior college }=15, \text { undergraduate }=16, \text { master }=19 \text {, doctor }=22 ; \text { In the regression analysis, the } \\
\text { number of years of education was used as a continuous variable. } 2 \text {. The occupational classification of } \\
\text { fathers in this study was converted according to the Gold Thorpe scale (EGP). }\end{array}$} \\
\hline
\end{tabular}

\section{Model and Method}

Preliminary statistical analysis revealed that the per capita household income is divided into four levels from low to high, with $25 \%$ as a unit. The overall picture of household income and preschool opportunities is shown in Figure 1. Compared with the stable increase of household income, the percentage of preschool attendance increases gradually; meanwhile, the proportion of children not entering the kindergarten gradually decreases. 


\section{Figure 1. Income Level and Attendance.}

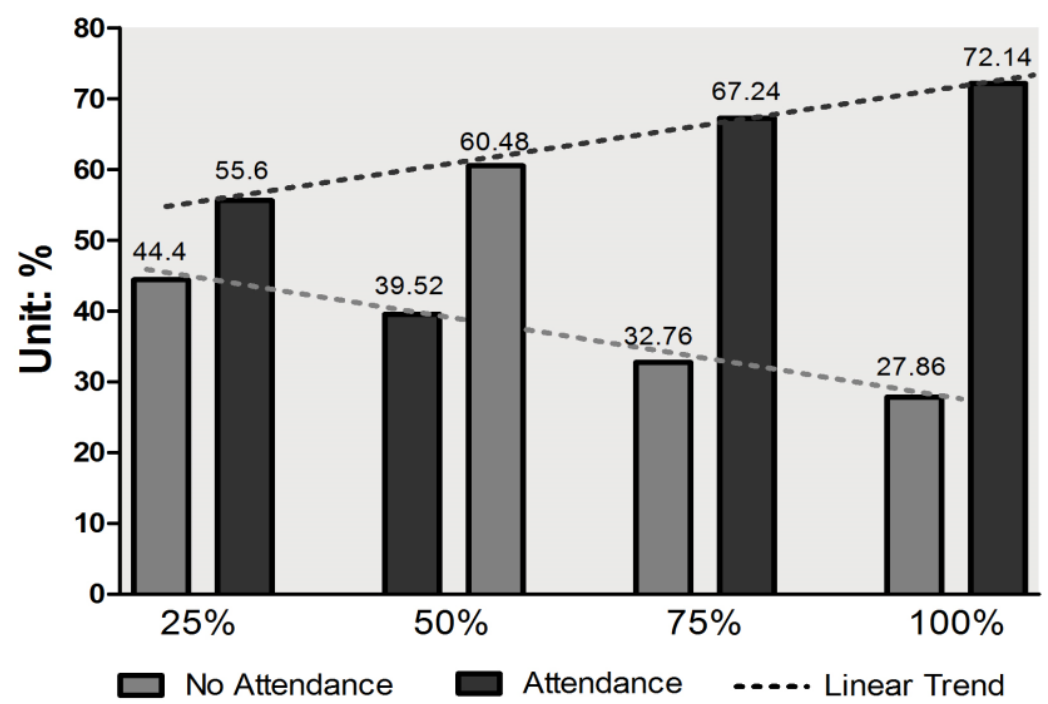

We conducted a $t$-test on the per capita income and preschool opportunities (Table 2), and found that the income level of the families with different choices was significantly different at the statistical level of $1 \%$. Specifically, the average per capita income of the families who chose to enter the kindergarten was 1,0543.2 CNY, while the average per capita income of the families who did not enter the kindergarten was 7,903.21 CNY. The average difference between the two groups was nearly $2,000 \mathrm{CNY}$.

\begin{tabular}{llll}
\hline \multicolumn{2}{l}{ Table 2. Family Income Gap of Different Choices (unit: CNY). } \\
\hline Variable & Group & M & T Value \\
\hline \multirow{2}{*}{ Preschool Attendance } & Yes & 10543.2 & \multirow{2}{*}{-4.403} \\
\cline { 2 - 3 } & No & 7903.21 & \\
\hline \multirow{2}{*}{ Preschool Type } & Public Kindergarten & 11661.7 & \multirow{2}{*}{$-3.1888^{* * *}$} \\
\cline { 2 - 3 } & Private Kindergarten & 9485.95 & \\
\hline Note. ${ }^{* * *}$ stands for significant at the $1 \%$ statistical level. & & \\
\hline
\end{tabular}


By comparison between the two groups of public and private kindergarten, the results reveal that the average per capita income is still significantly different at the statistical level of $1 \%$. This confirms that there are some correlations between household income and preschool choice. In addition, we want to know more about the extent to which family income influences the access to preschool education. Furthermore, we seek to confirm if there are other factors that also play a role in family educational choices. Therefore, we propose to test the above hypothesis through further empirical analysis.

Since the dependent variable $y$ is a binary variable, the multivariate logit model is adopted for analysis. The model is set as follows:

$$
\mathrm{y}^{*}=\beta_{\mathrm{o}}+\beta_{1} \text { income }+\sum_{\mathrm{i}=2}^{\mathrm{k}} \beta_{\mathrm{i}} \mathrm{x}_{\mathrm{i}}+\mathrm{u}
$$

Where $y^{*}$ is the potential variable, which represents the tendency of children to enter kindergarten, and it is the continuous variable. Income is the per capita income of a family. $x_{i}$ presents other factors affecting children's tendency to enrollment including gender, age, household registration status, and family size. $\mathrm{u}$ is a random distributed variable, subjecting to logistic distribution. The relationship between y and $\mathrm{y}^{*}$, the binary variable of whether children are enrolled in kindergarten, is as follows:

$$
y= \begin{cases}1, & y * \geq c \\ 0, & \mathrm{y} *<c\end{cases}
$$

Where c presents a certain critical value, $\mathrm{P}(\mathrm{y}=1)=\mathrm{P}\left(\mathrm{y}^{*} \geq \mathrm{c}\right)$ is the probability of entering the kindergarten, and $\mathrm{P}(\mathrm{y}=0)=\mathrm{P}\left(\mathrm{y}^{*} \leq \mathrm{c}\right)$ is the probability of not entering the kindergarten. The logit expression of the probability ratio of entering the kindergarten or not entering the kindergarten is as follows:

$$
\ln \frac{P(y=1 \mid X)}{P(y=0 \mid X)}=\beta_{0}+\beta_{1} \text { income }+\sum_{i=2}^{k} \beta_{i} x_{i}
$$

The coefficients can be obtained by using the maximum likelihood estimation method. We used the CFPS2012 database to measure the impact of per capita household income on children's enrollment. From the perspective of consumer demand theory, the utility of commodities not only comes from the inherent quality of commodities, but also depends on the consumption of other consumers and the price of commodities (Liu et al., 2008). When controlling for other family background factors, household income is the foundation of family buying education services, especially for the kindergarten fees varying in the competitive market, and preschool education 
service price directly affects the ability to buy and the category of education services required, so the estimated coefficient of the core explanatory variable is expected to be positive.

There are three choices that can be explained in terms of types of kindergarten entry (public kindergarten, high-fee private kindergarten, and low-fee private kindergarten), and multiple logit models are required (Mlogit). The private low-fee kindergarten is taken as the reference group. Suppose the probability of entering a public kindergarten, private high-fee kindergarten, and private low-fee kindergarten is $\mathrm{Pp}=$ $\mathrm{P}(\mathrm{y}=$ public $\mid \mathrm{X}), \mathrm{Ph}=\mathrm{P}(\mathrm{y}=$ high $\mid \mathrm{X})$ and $\mathrm{Pl}=\mathrm{P}(\mathrm{y}=\operatorname{low} \mid \mathrm{X})$, then the logit expression of their probability ratio is:

$$
\begin{gathered}
\ln \frac{P(y=\text { public } \mid X)}{P(y=\operatorname{low} \mid X)}=\beta_{o p}+\beta_{1 p} \text { income }+\sum_{i=2}^{k} \beta_{i p} x_{i} \\
\ln \frac{P(y=\operatorname{ligh} \mid X)}{P(y=\operatorname{low} \mid X)}=\beta_{o h}+\beta_{1 h} \text { income }+\sum_{i=2}^{k} \beta_{i h} x_{i}
\end{gathered}
$$

Similarly, two sets of coefficients in the above model can be obtained by using the maximum likelihood estimation method.

\section{Results}

\section{The Relationship between Household Income and Kindergarten Opportunities}

Stepwise regression was used to analyze the sensitivity of the model. As shown in Table 3, model (1) is the benchmark model, demographic variables and regional stratification are added in model (2), and model (3) and model (4) control the cultural background and social political background of the family respectively.

It is estimated from model (1) that the influence of family income on children's preschool education opportunity presents statistical significance with a positive coefficient when no variables are controlled for. By examining the marginal impact of family income, the results indicate that a $100 \%$ increase in family income will increase the chance of children entering kindergarten by $4.8 \%$.

At the same time, after controlling for individual variables and regional dummy variables, the marginal impact of children entering the kindergarten will increase by $3.2 \%$ for every $100 \%$ increase in family income. After controlling for family cultural background, social background and political background successively in model (3) to model (4), the influence of household income on children's admission to kindergar- 


\section{Table 3. Regression Results of Family Income and Enrollment Opportunity.}

\begin{tabular}{|c|c|c|c|c|c|}
\hline Variable & & (1) & $(2)$ & (3) & (4) \\
\hline \multirow{3}{*}{$\begin{array}{l}\text { Key Explanatory } \\
\text { Variable }\end{array}$} & \multirow{2}{*}{ Household Income } & $0.214^{* * *}$ & $0.207^{* * *}$ & $0.167^{* \star}$ & $0.174^{\star \star}$ \\
\hline & & $(0.049)$ & $(0.062)$ & $(0.067)$ & $(0.075)$ \\
\hline & Marginal Effect & $0.048^{* \star *}$ & $0.032^{* \star *}$ & $0.025^{\star \star}$ & $0.026^{\star *}$ \\
\hline \multirow{10}{*}{$\begin{array}{l}\text { Other Individual } \\
\text { Variables }\end{array}$} & \multirow{2}{*}{ Women } & & 0.131 & 0.103 & -0.030 \\
\hline & & & $(0.161)$ & $(0.172)$ & $(0.190)$ \\
\hline & \multirow{2}{*}{ Age } & & $1.562^{* * *}$ & $1.583^{* * *}$ & $1.670^{* * *}$ \\
\hline & & & $(0.114)$ & $(0.121)$ & $(0.133)$ \\
\hline & \multirow{2}{*}{$\begin{array}{l}\text { Non-agricultural Household } \\
\text { Registration Status }\end{array}$} & & $0.718^{* * *}$ & $0.565^{* *}$ & $0.572^{* *}$ \\
\hline & & & $(0.226)$ & $(0.251)$ & $(0.286)$ \\
\hline & \multirow{2}{*}{ Household Number } & & $-0.119^{\star \star \star}$ & $-0.160^{* \star *}$ & $0.151^{\star * *}$ \\
\hline & & & $(0.046)$ & $(0.049)$ & $(0.052)$ \\
\hline & \multirow{2}{*}{ Mother Doesn't Live at Home } & & 0.292 & 0.298 & $0.498^{*}$ \\
\hline & & & $(0.219)$ & $(0.225)$ & $(0.259)$ \\
\hline \multirow{4}{*}{ Region } & \multirow{2}{*}{ Ease } & & $1.070^{\star * *}$ & $1.048^{\star * *}$ & $1.134^{* * *}$ \\
\hline & & & $(0.201)$ & $(0.211)$ & $(0.232)$ \\
\hline & \multirow{2}{*}{ Middle } & & $1.497^{\star * *}$ & $1.645^{\star * \star}$ & $1.835^{\star \star *}$ \\
\hline & & & $(0.207)$ & $(0.224)$ & $(0.251)$ \\
\hline \multirow{8}{*}{$\begin{array}{l}\text { Cultural Back- } \\
\text { ground }\end{array}$} & \multirow{2}{*}{ Father's Years of Schooling } & & & -0.020 & -0.026 \\
\hline & & & & $(0.023)$ & $(0.027)$ \\
\hline & \multirow{2}{*}{ Mother's Years of Schooling } & & & 0.020 & 0.027 \\
\hline & & & & $(0.031)$ & $(0.037)$ \\
\hline & \multirow{2}{*}{ Communication Frequency } & & & 0.079 & 0.091 \\
\hline & & & & $(0.066)$ & $(0.072)$ \\
\hline & \multirow{2}{*}{ Buying Books } & & & $0.235^{\star *}$ & 0.121 \\
\hline & & & & $(0.099)$ & $(0.110)$ \\
\hline \multirow{2}{*}{ Social Background } & \multirow{2}{*}{ Father's Occupational Class } & & & & 0.019 \\
\hline & & & & & $(0.032)$ \\
\hline \multirow{2}{*}{$\begin{array}{l}\text { Political Back- } \\
\text { ground }\end{array}$} & \multirow{2}{*}{ Father Is a Party Member } & & & & 0.359 \\
\hline & & & & & $(0.278)$ \\
\hline \multirow{2}{*}{ Constant Term } & & $-1.264^{\star * *}$ & $-7.823^{\star * *}$ & $-7.885^{\star * *}$ & $-8.584^{* *}$ \\
\hline & & $(0.427)$ & $(0.848)$ & $(0.913)$ & $(1.135)$ \\
\hline $\mathrm{N}$ & & 1069 & 999 & 910 & 779 \\
\hline Pseudo $\mathrm{R}^{2}$ & & 0.013 & 0.267 & 0.282 & 0.301 \\
\hline
\end{tabular}


ten continued to be significant, and the marginal influence value remained continuous at about $2.6 \%$.

It can be seen from model (2) that children's age has a significant influence on children's admission to kindergarten, and the coefficient is significantly positive. This may reflect that family is more likely to send their children to kindergarten when children are readier to be adapted to the kindergarten environment. The gender difference does not show a significant difference in the opportunity to enter the kindergartens, which is inconsistent with the results of some previous studies, which show that boys are more likely to enter the kindergarten (Gong et al., 2015; Hannum, Werum, Fuller, \& Baker, 2003). It can be inferred from this that, with the development of society, people may gradually abandon the traditional "son preference" in the concept of education. Family size has a significantly negative impact on children's enrollment, indicating that the larger the number of families, the greater the expenditure pressure that the family income has to bear. Only when the survival needs of the whole family are met can the family consider its educational needs. Fuller and Liang (1996) also showed that the family size was negatively correlated with the availability of county kindergarten centers in the county and district in the United States. Regional factors also show significant differences in the opportunity for children to enter the kindergarten. Compared with the western region, the enrollment rate of children in the eastern and central regions is higher, which is basically consistent with the regional imbalance in the development of preschool education.

When model (3) controlled for parents' education background, it was found that parents' years of education had no statistically significant influence on children's chances of entering the kindergarten. The frequency of families purchasing books for their children has a significant impact on their access to preschool education, indicating that the higher the investment of families in cultural products for their children, the more likely they are to send their children to kindergartens. In model (4) and model (5), we added the family social background and political background respectively and concluded that the occupational background of their father had no significant influence on preschool attendance, but the coefficient was positive. Family political capital has no significant influence on children's preschool education, which is similar to Ye's preliminary conclusion (Ye, 2012), but he then examined the influence of grandparents' political resources and found that the capital advantage of intergenerational effect was significant. However, due to the limit of relevant indicators, it was impossible to further test the capital advantage of grandparents.

Finally, we considered the robustness check through filling the missing value, and found that the results have no changes, still presenting statistical significance at the $1 \%$ level and the standard errors are reduced. This shows that the relationship between household income and preschool opportunity is stable and significant. 


\section{Differential Relationships between Household Income and Kindergarten Opportu- nities}

In order to further estimate the influence of different family income starting points on the enrollment opportunity, we selected $25 \%, 50 \%$, and $75 \%$ as the starting points of four different levels of family income. The results are shown in Table 4.

It is evident from Table 4 that there are significant differences in the marginal effects of income for families with different income levels. The marginal effect of household income at the $50 \%$ percentile presents statistical significance, while the marginal effect on the remaining percentiles is not significant. The regression coefficient of each income locus was positive, and the basic conclusion was consistent with the logit regression results, indicating that the results were robust. From the perspective of marginal effect value, the overall change shows a trend of increasing first and then decreasing. The maximum marginal effect appears at the income sub-point of $50 \%$, which shows that if the income is doubled, the children's opportunities of entering the kindergarten will increase by $8.3 \%$. For the sample in this study, this means that the per capita household income increases from 3,000 CNY to 6,000 $\mathrm{CNY}$, and the child enrollment rate increases by $8.3 \%$. Once the median income level is exceeded, the marginal impact of household income gradually decreases with the increase of income level. Figure 2 visually depicts the change of marginal contribution of family income to the opportunity to enter the kindergarten. As is evident from the changing trend in Figure 2, the marginal impact of per capita household income on the preschool opportunity basically presents an inverted u-shaped changing trend, which goes up first and then goes down.

\section{Disparity in Kindergarten Opportunities between Rural and Urban Children}

Since the reform and opening up, the increasing disparities in household income may result in the inequality of educational opportunities between urban and rural areas. Under the background of the dual economic structure in urban and rural areas, there are significant differences between urban and rural families in terms of income, wealth, parents' education level, and other aspects (Sun \& Yan, 2015). In order to further examine the effect of family income on children's school opportunities by region, we also conducted a sample regression for children with different household registration status. The results are shown in Table 5.

Controlling for other factors, children's preschool education in urban areas is not significantly influenced by household income, but the coefficient value is still positive. For rural families, household income has statistical significance for children's chances of enrolling in kindergartens, which illustrates that every $100 \%$ increase in family income will increase the chance of children's enrolling in schools by $3 \%$. The results indicate that the influence of family income level on the opportunity 


\section{Table 4. Estimation Results Based on Different Income Quartiles.}

\begin{tabular}{llll} 
Family income point & $\mathbf{P 2 5}$ & $\mathbf{P 5 0}$ & $\mathbf{P 7 5}$ \\
\hline \multirow{2}{*}{ Preschool Attendance } & 0.047 & $0.558^{\star \star *}$ & 0.283 \\
\cline { 2 - 4 } & $(0.258)$ & $(0.277)$ & $(0.276)$ \\
\hline Marginal Effect & 0.007 & $0.083^{* * *}$ & 0.042 \\
\hline Other Control Variables & yes & Yes & yes \\
\hline Note. $\mathrm{N}=779$, Pseudo R2 $=0.032$. & & & \\
\hline
\end{tabular}

\section{Figure 2. The Marginal Effect of Family Income Quartile on Preschool Attend-} ance.

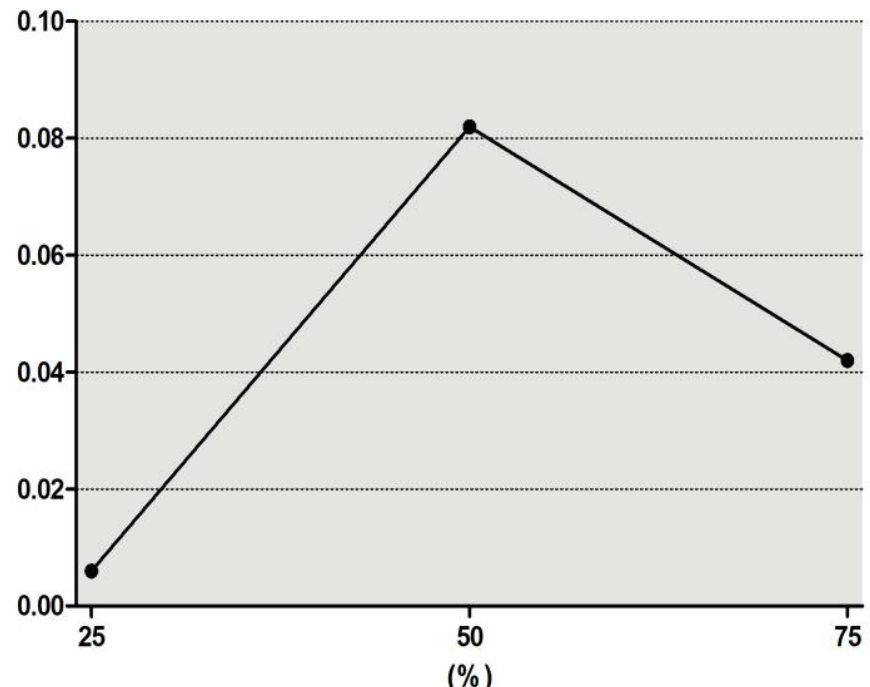

Table 5. Sample Regression in Urban and Rural Areas.

\begin{tabular}{llll}
\hline Household Income & Whole Samples & Urban Sample & Rural Samples \\
\hline \multirow{2}{*}{ Preschool Attendance } & $0.174^{* *}$ & 0.089 & $0.196^{* *}$ \\
\cline { 2 - 4 } & $(0.075)$ & $(0.243)$ & $(0.085)$ \\
\hline Marginal Effect & $0.026^{* *}$ & 0.010 & $0.030^{* *}$ \\
\hline Control for Other Variables & Yes & Yes & Yes \\
\hline $\mathrm{N}$ & 1195 & 271 & 924 \\
\hline The Pseudo $\mathrm{R}^{2}$ & 0.301 & 0.268 & 0.032 \\
\hline
\end{tabular}


Table 6. Mlogit Regression Results of Family Income and Kindergarten Choice.

\begin{tabular}{|c|c|c|}
\hline $\begin{array}{l}\text { Reference Group } \\
\text { (Private Low Fee Kindergarten) }\end{array}$ & Public Kindergarten & $\begin{array}{l}\text { Private High Fee } \\
\text { Kindergarten }\end{array}$ \\
\hline \multirow{2}{*}{ Household Income } & $0.227^{\star *}$ & 0.691 \\
\hline & $(0.101)$ & $(0.486)$ \\
\hline Marginal Effect & $0.041^{* *}$ & 0.010 \\
\hline Other Control Variables & yes & yes \\
\hline $\mathrm{N}$ & 227 & 230 \\
\hline The Pseudo $R^{2}$ & 0.126 & 0.126 \\
\hline
\end{tabular}

of children with different household registration is different. Compared with children in urban areas, the opportunities of rural children are more susceptible to the influence of family income. Because the expenditure of preschool education accounts for a small proportion in the high level of urban consumption expenditure, family income has little influence on the opportunity of preschool education. For rural families, the education investment is a burden almost entirely on the family, low family income and high education cost being the main obstacles for their children to receive preschool education. The household income also affects the opportunities of university education of rural and urban children. One study found that the effect of household income on university education opportunities is more significant for children in rural areas than that of students in urban areas, which is similar to the above estimated results (Xu \& Zong, 2016).

\section{The Relationship between Household Income and Kindergarten Types}

According to the children's questionnaire item, "what kind of kindergarten/preschool does the child attend?", the children are divided into two categories: public kindergarten and private kindergarten. At the same time, according to the item "what is the fee for the latest month of kindergarten/preschool?", children entering private kindergartens are further divided into two categories: high fee and low fee ${ }^{3}$. Specific results are shown in Table 6.

All the selected children were taken as samples to be examined and analyzed by taking private low-fee kindergartens as the reference group. The results indicate that the attendance to public kindergarten was significantly affected by the household 
income at the statistical level of 5\%. Every 100\% increase in family income increases the probability of children's access to public kindergartens by $4.3 \%$. Compared with entering private low fee kindergartens, the access to private high fee kindergartens does not significantly correlate with household income, even the marginal effect value is positive. It is evident from the regression results that the families with higher family income prefer public kindergartens to private kindergartens.

\section{Comparison of Results by Follow-Up Rounds}

Considering the comparability of the results, we used CFPS2014 data to conduct an empirical test on the children's admission to the kindergarten in that year by the reference of CFPS2012, and analyzed the relevant differences between the regression results in 2012 and 2014, so as to investigate the development trend of admission in different years. The comparison results indicate that: first, the significant influence of household income on preschool education still exists at the statistical level of $10 \%$. Specifically, every $100 \%$ increase in family income will increase children's chances of enrolling in kindergartens by $2.2 \%$.

Second, compared with the entry into private low-fee kindergartens, the marginal effect of family income on children's choice to enter public kindergarten is no longer significant, but the coefficient is positive.

Third, compared with the results in 2012, the influence of family income on the preschool opportunity in 2014 was significantly decreased at the statistical level, which was reflected in the significant reduction of the marginal influence of income. At the same time, household income has no significant influence on the kindergarten type. To some extent, this conclusion highlights the remarkable achievements of the First Phase of the Three-Year Action Plan for Preschool Education (2011-2013). Since 2011, the Three-Year Action Plan for Preschool Education has been put into effect. Preschool education investments have increased rapidly nationwide. From the perspective of the average investment in preschool education, the total investment increased from 921.02 CNY in 2009 to 4,513.98 CNY in 2013, an increase of 3.90 times. The steady growth of per pupil expenditure provides an important guarantee for the educational improvement, and also drives the enthusiasm of local governments to invest in preschool education. By the beginning of 2012, the number of public kindergartens and private kindergartens in Gansu province had increased to 1,280 and 1,445 respectively, which was significantly higher than that of 2010, and the number of private kindergartens was slightly higher than that of public kindergartens (Shen \& Li, 2013). By the end of 2013, the number of kindergartens runs by enterprises and institutions in Heilongjiang province increased by 1,177 compared with 2010 , with a growth rate of $35.27 \%$. 
In conclusion, in terms of both the quantity and quality of preschool education resources, the public has a wider selection of kindergartens. Furthermore, under the trend of the rapid development of inclusive kindergartens, the influence of family income on children's access to preschool education has been gradually weakened.

\section{Conclusions and Implications}

Equal preschool education is the starting point of educational equity, and access to preschool education at this stage has a positive impact on individuals, families, and even the society. There has been research confirming that family economic background has a significant positive effect on educational attainment, but there are few similar studies in the field of early childhood education. Aiming to estimate the influence of family income on preschool education opportunity, we utilized the CFPS database to investigate the influence of family income on children's enrollment opportunity and choice, based on the Logit Model and Multinomial Logit Model. The specific conclusions are as follows:

(i) Family income has a significant impact on preschool education en-rollment. Every $100 \%$ increase in household income increases a child's chances of entering preschool education by $2.6 \%$ according to 2012 CFPS data. Based on the above results, we tested the heterogeneity of children's choice in kindergartens, and found that: compared with entering private kindergartens with low fees, family income can significantly increase the opportunities for entering public kindergarten, while it has no effect on entering private kindergartens. The CFPS2014 database showed a similar marginal effect $(2.2 \%)$.

(ii) Compared with the central and eastern regions, the enrollment rate of children in the western regions is significantly lower. At the same time, family size significantly affects children's preschool opportunities; that is, the larger the number of families, the lower the children's kindergarten attendance opportunities.

(iii) The findings indicate that the preschool opportunities of rural children are significantly affected by their household income which has no impact for urban children comparably. It is evident that the family income is an important factor for rural children to consider whether they can receive preschool education. If the family cannot afford the full amount of preschool education funds, children may not have the opportunity to enter kindergartens.

The conclusions of this study provide the following implications:

(1) Children in low-income families can achieve a better performance than children from middle class families through preschool education, which 
has a larger marginal effect (Bai and Xiong, 2012). In order to better reflect the public welfare of preschool education and ensure the fairness and efficiency of the preschool education market, many countries directly or indirectly distribute financial funds to the families of young children. The Australian government stopped providing subsidies to preschool education institutions and began to provide subsidies to parents of young children. Denmark, the Netherlands, France, and other countries have also adopted the mode of co-supply of education service providers and demanders to reduce family expenditures on preschool education.

At the same time, compared with urban families, rural families' income has a greater impact on children's preschool chances. Due to the differences in educational development between urban and rural areas, the rational allocation of educational resources and improvement of resource utilization efficiency will be the focus of early childhood education development in the future. From the experience of field research on rural kindergartens, it is evident that the facilities of kindergartens in rural areas have been gradually supplemented and improved, and the infrastructure construction of township central kindergartens has been heavily invested in. However, the weak teaching staff, extremely limited financial aid, and the lack of effective supervision still limit the improvement of rural preschool education. The principal problem faced by the development of rural kindergartens is that it is difficult to purchase high quality services, even if the same amount of money is spent.

(2) According to the empirical analysis results, an increase of family income will increase the preschool education possibility, which means that children from low-income families, especially those from rural low-income families, are more likely to enter private kindergartens. Therefore, the administrative department should actively guide and supervise the development level and quality of private kindergartens, so that quality and quantity go hand in hand. Local government needs to build systematic indicators for educational investment and supervision based on the supply capacity and output quality of private kindergartens.

Although this study makes an objective estimation of family income and preschool education opportunities with national samples, it still possesses the following limitations: first, whether it is reasonable or not to divide kindergartens into public kindergartens, private high fee kindergartens, and private low fee kindergartens may still need discussion. Furthermore, there are no comprehensive databases to estimate the relationship of household income and preschool quality. If the relationship between family income and children's selection needs to be understood more accurately, 
then information collection and the evaluation of kindergarten quality should be strengthened. Second, due to limited data, in addition to controlling for family background factors, this study fails to further control the individual development differences of school-age children, which may affect whether they can receive preschool education.

\section{Notes}

1 Excluding Xinjiang Uygur Autonomous region, Tibet Autonomous region, Qinghai province, Inner Mongolia Autonomous region, Ningxia Hui Autonomous region, Hainan province, and Hong Kong, Macao and Taiwan regions.

2 The CFPS2010 data were not used in this study because it lacked key indicators of the kindergarten category for children aged 3-6 years, such as whether they attended public or private kindergartens.

3 According to the latest monthly fee of the institute, the monthly fee is higher than 1200 CNY.

\section{Acknowledgement}

This study is the periodical research result of the youth fund project of humanities and social science research of the Ministry of Education "research on the source and turnover of preschool teachers in poor rural areas of Hubei province" (16YJCZH022). Thanks must go to the professional feedback from Dr. Renjun Chen, Drs. Hongmei Ma, Xu Wang, Zhenyi Li, and Jiali Zhang.

\section{References}

Bai, T., Xiong, X. Y., \& Wang, S. J. (2012) An analysis on the preschool education financing in china. Education \& Economy; 1: 2933. (in Chinese)

Bassok, D., Fitzpatrick, M., \& Loeb, S. (2011) Disparities in child care availability across communities: differential reflection of targeted interventions and local demand. Retrieved from

https://cepa.stanford.edu/content/disparitieschild-care-availability-across-communitiesdifferential-reflection-targeted-interventionsand-local-demand

Bennett, J. (2008) Early childhood services in the OECD countries: review of the literature and current policy in the early childhood field. UNICEF working papers. Retrieved from

https://www.unicef-irc.org/publications/502early-childhood-services-in-the-oecd- countries-review-of-the-literature-andcurrent.html

Brown, P. H. (2006) Parental education and investment in children's human capital in rural china. Economic Development \& Cultural Change; 54(4): 759-789.

Chiswick, B. R., \& Debburman, N. (2004) Preschool enrollment: An analysis by immigrant generation. Social Science Research; 35(1): 60-87.

Connelly, D. R. (2005). The influences of local price and availability on parents" choice of child care. Population Research and Policy Review.

Cui, S. Q., CNY, L. S., \& Tian, Z. L. (2011) On the role of the government in the development of preschool education - based on the analysis of economic theory and practical experience. Studies in Preschool Education; 197(5): 3-8. (in Chinese) 
Fang, C. C. (2011) The influences of family background on individual's educational attainment: an analysis from the perspective of residential differentiation. Journal of Educational Studies; 6: 118-126. (in Chinese)

Foguel, M. N., \& Veloso, F. A. (2014) Inequality of opportunity in daycare and preschool services in Brazil. Journal of Economic Inequality; 12(2): 191-220.

Fuller, B., Holloway, S. D., \& Liang, X. (1996) Family selection of child-care centers: the influence of household support, ethnicity, and parental practices. Child Development; 67(6): 3320-3337.

Fuller, B., \& Liang, X. (1996) Market failure? estimating inequality in preschool availability. Educational Evaluation \& Policy Analysis; 18(1): 31-49.

Gong, X., Xu, D., \& Han, W. J. (2015) Household income and preschool attendance in china. Child Development; 86(1): 194-208.

Hannum, E., Werum, R., Fuller, B., \& Baker, D. (2003) Grandmothers, formal care, and educational advantage in china. Research in the Sociology of Education; 14(03): 7-31.

Hong, X. M., \& Luo, L. (2012) Analysis of the differences in preschool education development in urban and rural china from the prospective of education equity. Journal of Educational Studies; 8(5): 73-81. (in Chinese)

Liu, G. Y., Chen, Y. Y., \& Chen, W. W. (2016) Research on the preschool education opportunities of children with different background from the perspective of education equity - based on the investigation data of shenzhen. Education \& Economy; 5: 23-29. (in Chinese)
Liu, Y., Li, Z. Y., \& Pan, Y. J. (2008) Comparative study on environment quality of kindergartens of different financial input and management system. Studies in Preschool Education; 164(08): 7-11. (in Chinese)

Liu, Z. L., \& Gao, B. C. (2013) Research on the comprehensive development level of preschool education. Educational Research; 399(4): 30-37. (in Chinese)

Song, Z. M., \& Liu, X. L. (2013) Investment on the preschool education of urban lowincome families. Studies in Preschool Education; 219(3): 39-49. (in Chinese)

Wang, H. M., W, Y. X., \& Huang, C. (2017) Family socioeconomic status, preschool education and the adolescents' cognitive \& non-cognitive abilities. Youth Studies. (in Chinese)

Xia, J., Pang, L. J., \& Zhang, X. (2014) On china's policy on institutional reform of early childhood education investment. Studies in Preschool Education; (8): 19-23. (in Chinese)

Xing, Y., \& Hu, Y. M. (2015) Access to preschooling for migrant children in Mainland China: With Special Reference to Socioeconomic Background \& Migration Pattern. Education \& Economy; 3: 52-57. (in Chinese)

Xu, J., \& Zong, Q, Q. (2016) Household income and children's higher education opportunities in China during the transition period. World Economic Papers; 6: 24-41. (in Chinese)

Ye, X, Y., (2012) "School choice by right": parents' political capital and children's school choice. World Economic Papers; 4: 52-73. (in Chinese).

Received: 20 February 2019

Revised: 07 March 2019

Accepted: 19 March 2019

The Chinese version of this article has been published in Research in Educational Development 2018; 38(Z2):18-26. The English version has been authorized for being publication in BECE by the author(s) and the Chinese journal.

王鹏程, 龚欣. 家庭收入与学前教育机会一基于 CFPS 数据的实证研究. 教育发展研究 2018; 38(Z2):18-26. 